\title{
1-MCP nos aspectos fisiológicos e na qualidade pós-colheita de maçãs Eva durante 0 armazenamento refrigerado
}

\author{
1-MCP on physiological and postharvest quality of apples Eva during refrigerated stored
}

\author{
Camila Argenta Fante ${ }^{\mathrm{I}}$ Ana Carolina Vilas Boas ${ }^{\mathrm{II}}$ Adriano Carvalho Costa ${ }^{\mathrm{II}}$ Edson Pablo Silva ${ }^{\mathrm{II}}$ \\ Marcelo Caetano de Oliveira ${ }^{I I}$ Luiz Carlos de Oliveira Lima ${ }^{\text {II }}$
}

\section{RESUMO}

O objetivo deste estudo foi verificar o efeito de doses específicas do composto 1-metilciclopropeno (1-MCP), após a colheita, nos aspectos fisiológicos e na qualidade físico-química de maçãs Eva durante o armazenamento refrigerado. Após a aplicação dos tratamentos com diferentes doses de 1-MCP $(0,10$, 50,100 e $500 \mathrm{mg} \mathrm{L}^{-1}$ ), os frutos foram armazenados em câmara fria $0,5^{\circ} \mathrm{C}( \pm 0,5)$ por até 135 dias. $O$ armazenamento refrigerado juntamente com a aplicação de 1-MCP resultou em uma menor produção de etileno, principalmente nos frutos tratados com as doses de 10, 50 e 100 $\mathrm{mg} \mathrm{L}^{-1}$. O grupo controle perdeu $45 \%$ de sua firmeza, enquanto os grupos tratados perderam, em média, $27 \%$ de sua firmeza. O parâmetro C de cor identificou frutos com cor mais intensa aos 135 dias de armazenamento e o ângulo Hue mostrou que, quando tratados com as doses de 10 e $50 \mathrm{mg} \mathrm{L}^{-1}$, os frutos apresentaram-se mais amarelados, evidenciando melhor ação do 1-MCP em baixas concentrações. Frutos que não foram submetidos aos tratamentos apresentaram maior relação sólidos solúveis e acidez, demonstrando assim maior atividade metabólica.

Palavras-chave: qualidade, etileno, taxa respiratória.

\section{ABSTRACT}

The objective of this study was to investigate the effect of specific doses of the compound 1-methylcyclopropene (1$M C P)$, after harvest, on the physiological and physicochemical quality of apples Eva during refrigerated storage. After applying thetreatment with different doses of 1-MCP $(0,10,50,100$ and $\left.500 \mathrm{mg} \mathrm{L}^{-1}\right)$, fruit were stored in cold $0.5^{\circ} \mathrm{C}( \pm 0.5)$ for up to 135 days. The cold storage with the application of 1-MCP resulted in a lower production of ethylene in fruits treated with doses of 10, 50 and $100 \mathrm{mg} \mathrm{L}^{-1}$. The control group lost $45 \%$ of its firmness, while the treated groups lost on average $27 \%$ of their firmness the parameter $C$ fruit color identified with a more intense color to the 135 days of storage and Hue angle showed that when treated with doses of 10 and $50 \mathrm{mg} \mathrm{L}^{-1}$, fruit showed more yellow, evidenced best action of 1-MCP at low concentrations. Fruit that have not undergone the treatments showed a higher ratio of soluble solids and acidity, thus demonstrating increased metabolic activity.

Key words: quality, ethylene, respiratory rate.

\section{INTRODUÇÃO}

Desenvolvida em 1979, a cultivar de maçã 'Eva' tem apresentado um aumento potencial de produtividade, pois é uma cultura que possui baixa necessidade por períodos de frio, sendo cultivada principalmente no estado de Minas Gerais. Por ser uma cultivar precoce, a 'Eva' tem sua colheita, geralmente, entre os meses de novembro e janeiro, o que facilita a sua comercialização (HAUAGGE \& TSUNETA, 1999).

As condições de armazenamento e os métodos de conservação pós-colheita que buscam a manutenção da qualidade a fim de maximizar a vida pós-colheita das maçãs Eva ainda não foram totalmente estudados. Uma das técnicas mais eficientes para aumentar a durabilidade de frutos, minimizar as perdas pós-colheita e diminuir a taxa respiratória é o armazenamento à baixa temperatura. No entanto, é necessário associar à refrigeração outros métodos de conservação para melhor preservar os aspectos de qualidade pós-colheita.

O etileno é conhecido como o hormônio do amadurecimento que desencadeia uma série de transformações bioquímicas que culminam no

IFaculdade de Farmácia, Universidade Federal de Minas Gerais (UFMG), 31270-901, Belo Horizonte, MG, Brasil. E-mail: camilafante@farmacia.ufmg.br. Autor para correspondência.

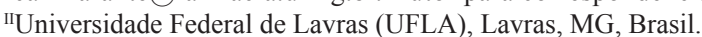


amadurecimento e na senescência dos frutos (MA et al., 2006). O composto volátil 1-MCP liga-se permanentemente aos receptores de etileno do tecido dos frutos (HALL et al., 2000; BRACKMANN et al., 2010) e impede a ação do etileno (AMBAW et al., 2011). Assim, a aplicação pós-colheita de 1-MCP pode manter a qualidade de maçãs, inibir o desenvolvimento de algumas desordens fisiológicas durante o armazenamento, além de demonstrar seu efeito positivo no potencial de conservação, provocando atrasos no amadurecimento e melhoria na retenção da firmeza (BRACKMANN et al., 2004; CORRENT et al., 2005).

Devido ao fato de o 1-MCP ser ativo em concentrações muito baixas, ter seu resíduo desprezível e ser considerado não nocivo para seres humanos e para o meio ambiente, apresenta-se como uma ferramenta para manter a qualidade dos produtos hortícolas (LUO et al., 2007). Assim, o objetivo deste estudo foi verificar o efeito de doses específicas de 1-MCP, após a colheita, nos aspectos fisiológicos e na qualidade físico-química de maçãs Eva durante o armazenamento refrigerado.

\section{MATERIAL E MÉTODOS}

Maçãs (cultivar 'Eva') foram adquiridas em pomar comercial no estado de Minas Gerais, Brasil, durante a safra 2009/10. As amostras foram sanitizadas com hipoclorito de sódio $100 \mathrm{mg} \mathrm{L}^{-1}$ por 10 minutos e posteriormente selecionadas quanto à aparência, ausência de injúrias e podridões. Para montagem do experimento, foi utilizado um delineamento inteiramente casualizado com cinco repetições por tratamento e unidade experimental composta por cinco frutos. Os tratamentos utilizados envolveram doses de $0,10,50,100$ e $500 \mathrm{mg} \mathrm{L}^{-1}$ de 1-MCP, obtido de uma formulação em pó contendo $0,14 \%$ deste produto. Depois de calculada cada concentração necessária para os devidos tratamentos, estas foram solubilizadas individualmente em água à temperatura ambiente em recipientes herméticos e, posteriormente, cada solução foi acondicionada aberta juntamente com os frutos em caixas de isopor, com volume de 80 litros, com imediato fechamento destas. Os frutos ficaram expostos ao tratamento por 12 horas à temperatura de $23^{\circ} \mathrm{C}( \pm 2)$.

Antes da aplicação dos tratamentos, cinco amostras de seis frutos foram analisadas para determinar a condição inicial média das maçãs, caracterizando o dia 0 (zero) de armazenamento. Nesse dia, não foi detectada liberação de $\mathrm{CO}_{2} \mathrm{~kg}^{-1} \mathrm{~h}^{-1}$ e a produção de etileno foi de $814 \mu \mathrm{Lg}^{-1} \mathrm{~h}^{-1}$, sendo que os frutos apresentavam firmeza de polpa de 47,36N (sem casca), sólidos solúveis de $11,5^{\circ}$ Brix, acidez titulável de $0,436 \%$ de ácido málico e cor de fundo da epiderme com valor de L* igual a 77,29, Chroma de 40,3 e ângulo Hue de $99,7^{\circ} \mathrm{h}$. Após a aplicação dos tratamentos, os frutos foram armazenados em câmara fria à $0,5^{\circ} \mathrm{C}( \pm 0,5)$ e umidade relativa de $93 \%( \pm 2)$ durante 135 dias. As propriedades físicas e físicoquímicas foram avaliadas a cada 45 dias do período experimental.

Para análise da taxa respiratória e produção de etileno, em cada período experimental, os frutos foram colocados em frascos de $820 \mathrm{~mL}$, os quais foram hermeticamente fechados durante uma hora $\mathrm{e}$ mantidos na mesma temperatura de armazenamento. Após esse período, foram retiradas as amostras de gases para a taxa respiratória (teor de $\mathrm{CO}_{2}$ determinado por PBI Dan sensor Modelo 9900) e etileno por meio de um septo de silicone existente na tampa do frasco. Para determinação de etileno, alíquotas do gás foram retiradas em tubos a vácuo de $10 \mathrm{~mL}$. Por meio de uma seringa, retirou-se $1 \mathrm{~mL}$ de amostra dos tubos para injeção em cromatógrafo gasoso, Modelo VarianChrompack CP-3800, equipado com detector de ionização de chamas e nas seguintes condições: coluna empacotada Porapak Q; temperatura do injetor $250^{\circ} \mathrm{C}$; temperatura do detector $280^{\circ} \mathrm{C}$; programação da coluna com temperatura inicial de $90^{\circ} \mathrm{C}$, sendo a temperatura da coluna acrescida após 4,5 minutos a uma taxa de $100^{\circ} \mathrm{C}$ a cada minuto até atingir $220^{\circ} \mathrm{C}$ para limpeza da coluna; gás de arraste nitrogênio, com fluxo de $20 \mathrm{~mL} \mathrm{~min}^{-1}$ e pressão da coluna de 0,1 psi.

A coloração de fundo da epiderme foi medida nos lados opostos do fruto com auxílio de um colorímetro Minolta CR 400, no modo CIE L*a*b, sendo os valores de $\mathrm{L}^{*}$, Chroma (C) e ângulo Hue $\left(h^{\circ}\right)$ avaliados. A coordenada $L^{*}$ mede a claridade ou luminosidade da amostra, variando entre o preto (0) e o branco (100), e encontra-se pronta para análise, sendo utilizada para verificar o escurecimento. As variáveis $a^{*}$ e b* são utilizadas para cálculos que permitem a obtenção das coordenadas cilíndricas, que são ângulo de cor ou tonalidade $\left(\mathrm{h}^{\mathrm{o}}\right)$, que identifica a cor num ângulo de 360 graus e chroma $\left(\mathrm{C}^{*}\right)$ que representa a pureza da cor.

Calculou-se a cromaticidade de acordo com a seguinte equação: $C=\sqrt{a *^{2}+b *^{2}}$

Para o cálculo da tonalidade, empregou-se a fórmula do ângulo Hue, de acordo com os valores de $a^{*}$ e b* obtidos, da seguinte forma:

a)Valores de $a^{*}$ e $b^{*}>0: h^{0}=\operatorname{arctg}\left(b^{*} / a^{*}\right)$.

b)Valores de $a^{*}<0$ e b* $>0: h^{\circ}=180^{\circ}+\operatorname{arctg}\left(b^{*} / a^{*}\right)$. 
c) Valores de $a^{*}$ e $b^{*}<0: h^{o}=270^{\circ}+\operatorname{arctg}\left(b^{*} / a^{*}\right)$.

d)Valores de $\mathrm{a}^{*}>0$ e $\mathrm{b}^{*}<0: \mathrm{h}^{\circ}=360^{\circ}+\operatorname{arctg}\left(\mathrm{b}^{*} / \mathrm{a}^{*}\right)$.

A firmeza foi determinada individualmen-

te na região equatorial do fruto inteiro com auxílio de um penetrômetro Magness - Taylor, com sonda de 5/6 polegadas de diâmetro. A perda de massa foi avaliada pesando-se os frutos em balança semi-analítica. As análises de $\mathrm{pH}$ e acidez titulável foram realizadas conforme AOAC (2007). Os sólidos solúveis foram analisados utilizando-se refratômetro de Brix (AOAC, 2007) e a relação sólidos solúveis e acidez foi obtida pela divisão dos valores de sólidos solúveis pelo teor de acidez titulável.

Os resultados foram submetidos à análise da variância, sendo as médias comparadas entre si pelo teste de Scott-Knott, em nível de 5\% de probabilidade de erro, utilizando o programa computacional R Development Core Team (2010).

\section{RESULTADOS E DISCUSSÃO}

A atividade respiratória apresentou diferença significativa entre os tempos de armazenamento para todos os tratamentos com diferentes doses de 1-MCP (Tabela 1), sendo que, aos 90 dias de armazenamento em câmara refrigerada, os frutos apresentaram maior liberação de $\mathrm{CO}_{2}$ por quilo por hora, em relação ao135 dia. Cabe ressaltar que no dia em que a colheita foi realizada, ou seja, no dia zero de armazenamento e após 45 dias da colheita, todos os frutos analisados não apresentaram níveis detectáveis de $\mathrm{CO}_{2}$. Ainda na tabela 1, é possível observar a produção de etileno em maçãs da cultivar 'Eva'. É notório que os frutos controle e tratados com a dose de $10 \mathrm{mg} \mathrm{L}^{-1}$ apresentaram aumento na produção de etileno, pois, antes da aplicação dos tratamentos, no dia zero, foi detectada produção de etileno de $814,00 \mu \mathrm{L} \mathrm{g}^{-1} \mathrm{~h}^{-1}$. Para os frutos controle, esse aumento de produção de etileno ocorreu até os 90 dias de armazenamento $\left(12.507,00 \mu \mathrm{Lg}^{-1} \mathrm{~h}^{-1}\right)$, com posterior queda ao final do período de avaliação, devido, provavelmente, ao fim do período climatério e início da senescência. Já para os frutos tratados com $10 \mathrm{mg} \mathrm{L}^{-1}$ de 1-MCP, o aumento foi gradativo, pois a produção de etileno, que era de $839,00 \mu \mathrm{Lg}^{-1} \mathrm{~h}^{-1}$ aos 45 dias de armazenamento, aumentou para $4.152,00 \mu \mathrm{L}$ $\mathrm{g}^{-1} \mathrm{~h}^{-1}$ no $90^{\circ}$ dia e para $6.357,00 \mu \mathrm{Lg}^{-1} \mathrm{~h}^{-1}$ ao $135^{\circ}$ dia. Da mesma forma, a dose de $50 \mathrm{mg} \mathrm{L}^{-1}$ aumentou com o período de armazenamento, não apresentando queda característica de frutos climatéricos ao se aproximar do final do estudo, fato este que evidencia a atividade do 1-MCP que se liga permanentemente aos receptores de etileno. Com o tempo, novos sítios de ligação são formados, ocorrendo o aumento da produção de etileno e promoção de uma série de reações ligadas ao amadurecimento (HALL et al., 2000; BRACKMANN et al., 2010).

Frutos tratados com as doses de 10 e $50 \mathrm{mg}$ $\mathrm{L}^{-1}$, juntamente com a dose de $100 \mathrm{mg} \mathrm{L}^{-1}$, apresentaram produção de etileno semelhante estatisticamente aos 90 dias de armazenamento, diferenciando do tratamento controle e da dose de $500 \mathrm{mg} \mathrm{L}^{-1}$ que apresentaram maiores concentrações de etileno neste período. Ainda, foi possível observar que a dose de $100 \mathrm{mg} \mathrm{L}^{-1}$ não apresentou diferença significativa ao longo do tempo, demonstrando também um bom controle na ação do etileno. Já a dose de $500 \mathrm{mg} \mathrm{L}^{-1}$ apresentou o mesmo comportamento do controle quando se analisam as doses ao longo do tempo. No entanto, ao analisar os diferentes tratamentos em cada tempo, é possível afirmar que a dose de $500 \mathrm{mg} \mathrm{L}^{-1}$ é diferente estatisticamente do grupo controle, pois os frutos tratados com 1-MCP apresentaram menor produção de etileno, sendo ela de $6.708,00 \mu \mathrm{L} \mathrm{g}^{-1} \mathrm{~h}^{-1}$

Tabela 1 - Respiração e produção de etileno em maçã cv. 'Eva' aos 45, 90 e 135 dias de armazenamento refrigerado a $0,5^{\circ} \mathrm{C}$ ( $\pm 0,2$ ) em função da aplicação de 1-MCP em diferentes doses antes do armazenamento.

\begin{tabular}{|c|c|c|c|c|c|c|}
\hline \multirow{3}{*}{ Doses de 1-MCP $\left(\mathrm{mg} \mathrm{L}^{-1}\right)$} & \multirow{2}{*}{\multicolumn{3}{|c|}{--------Respiração $\left(\mathrm{mL} \mathrm{CO}_{2} \mathrm{~kg}^{-1} \mathrm{~h}^{-1}\right)$---------- }} & \multicolumn{3}{|c|}{---------Produção de etileno $\left(\mu \mathrm{L} \mathrm{g}^{-1} \mathrm{~h}^{-1}\right)$--- } \\
\hline & & & & \multicolumn{3}{|c|}{  } \\
\hline & 45 & 90 & 135 & 45 & 90 & 135 \\
\hline $0 \mathrm{CV}(\%)$ & *ND & $14,01 \mathrm{Ba} 0,08$ & 10,53 Aa20,66 & $1.476,0 \mathrm{Ab} 0,43$ & $12.507,0 \mathrm{Aa} 0,02$ & $4.199,0 \mathrm{Ab} 0,05$ \\
\hline $10 \mathrm{CV}(\%)$ & ND & 35,64 Aa14,76 & 10,79 Ab5,15 & $839,0 \mathrm{Ab} 1,31$ & $4.152,0 \mathrm{Cb} 0,04$ & $6.367,0$ Aa 0,25 \\
\hline $50 \mathrm{CV}(\%)$ & ND & 32,24 Aa11,16 & $10,79 \mathrm{Ab} 5,15$ & $168,0 \mathrm{Bb} 0,34$ & $2.863,0 \mathrm{Cb} 0,20$ & $4.402,0$ Aa 0,14 \\
\hline $100 \mathrm{CV}(\%)$ & ND & 21,39 Aa1,56 & 10,79 Ab5,15 & $72,0 \mathrm{Ba} 0,80$ & $699,0 \mathrm{Ca} 0,16$ & ND \\
\hline 500 CV (\%) & ND & 28,51 Aa1,55 & $7,30 \mathrm{Ab} 3,55$ & $156,0 \mathrm{Bb} 0,73$ & $6.708,0 \mathrm{Ba} 0,07$ & ND \\
\hline
\end{tabular}

*ND = abaixo do limite de detecção; médias com letras minúsculas iguais na mesma linha e maiúsculas na coluna não diferem significativamente entre si pelo teste de Scott-Knott a 5\% de probabilidade de erro. 
aos 90 dias de armazenamento e não detectada pelo equipamento aos 135 dias.

$\mathrm{Na}$ tabela 2, estão apresentados os valores de firmeza de polpa de maçãs da cultivar 'Eva' submetidas a diferentes doses de 1-MCP e armazenadas em ambiente refrigerado. É possível observar diferença estatística ao longo do período de armazenamento para todos os grupos em estudo, sendo que os valores obtidos no primeiro dia de avaliação são menores daqueles obtidos no dia da colheita $(47,36 \mathrm{~N})$, evidenciando diminuição da firmeza. No entanto, apesar de não haver diferença significativa entre os tratamentos, verifica-se que, ao final do período experimental, o grupo controle perdeu $45 \%$ de sua firmeza, enquanto que os grupos tratados com as doses de 10, 50, 100 e 500mg L $\mathrm{m}^{-1}$ perderam, respectivamente, 36, 28, 23 e 20\%. Em trabalho com maçãs da cultivar Royal Gala, BRACKMANN et al. (2010) demonstraram que, o 1-MCP reduziu a síntese de etileno e a respiração, mas esse efeito não influenciou na perda de firmeza das maçãs durante todo o período de armazenamento.

A perda da firmeza de polpa ao longo do armazenamento pode ser consequência do amadurecimento normal devido à ação do etileno. No entanto, como observado na tabela 1, o 1-MCP é capaz de reduzir a produção de etileno, o que é confirmado por um grande número de trabalhos (CORRENT et al., 2005; BRACKMANN et al., 2004, 2008; LARRIGAUDIÈRE et al., 2008; WEI et al., 2010). Desse modo, a perda de firmeza dos frutos com o decorrer do tempo pode ser devido à maturação ou pela considerável perda de massa, conforme apresentado na tabela 2. Ainda, segundo WEI et al. (2010), diferentes cultivares apresentam características diferentes para o mecanismo de amaciamento e para a variável firmeza, podendo ser encontradas respostas distintas. No entanto, o uso de baixas temperaturas e do 1-MCP desempenham papel importante com relação a esse parâmetro. Ainda, cabe ressaltar que variável $\mathrm{pH}$ não diferiu estatisticamente ao longo do período de armazenamento e entre os tratamentos, estando seus valores entre 3,48 e 3,71.

As maçãs comerciais podem ser classificadas de acordo com os valores de acidez titulável e de sólidos solúveis. Nesse contexto, a acidez titulável não diferiu entre os tratamentos, exceto para as doses de 10 e $50 \mathrm{mg} \mathrm{L}^{-1}$ no último dia de avaliação, que apresentaram-se maior estatisticamente $(0,85 \%$ e $0,80 \%$ de ácido málico, respectivamente) que as demais $(0,52 \%, 0,65 \%$ e $0,54 \%$ de ácido málico para doses de 0,100 e $500 \mathrm{mg} \mathrm{L}^{-1}$, respectivamente). Ainda, estas mesmas doses de 10 e $50 \mathrm{mg} \mathrm{L}^{-1}$ apresentaram um aumento gradativo nos valores desta variável ao longo do período de armazenamento, com valor de $0,53 \%$ para ambas aos 45 dias de armazenamento que passou para $0,63 \%$ e $0,67 \%$ de ácido málico aos 90 dias. Segundo CORRENT et al. (2005), o efeito do 1-MCP na promoção de valores mais elevados de acidez titulável pode ser explicado pela desaceleração do metabolismo dos frutos.

Os teores de sólidos solúveis e a relação sólidos solúveis e a acidez titulável estão apresentados na tabela 3. Os sólidos solúveis tendem a aumentar ao longo do armazenamento e com a maturação, sendo que este aumento pode ter sido provocado pela perda de massa apresentada na tabela 2 , provocando a sua concentração. Ao comparar os tratamentos no mesmo tempo de armazenamento, verifica-se semelhança estatística para a variável sólidos solúveis até o $90^{\circ}$ dia. Após, frutos tratados com a dose de $500 \mathrm{mgL}^{-1}$ e frutos controle apresentaram maiores valores para esse parâmetro. Segundo ANTUNES et al. (2003), o aumento de sólidos solúveis pode ser decorrente

Tabela 2 - Firmeza de polpa e perda de massa em maçã cv. 'Eva' aos 45, 90 e 135 dias de armazenamento refrigerado a $0,5^{\circ} \mathrm{C}( \pm 0,2) \mathrm{em}$ função da aplicação de 1-MCP, em diferentes doses antes do armazenamento.

\begin{tabular}{|c|c|c|c|c|c|c|}
\hline \multirow{3}{*}{ Doses 1-MCP $\left(\mathrm{mg} \mathrm{L}^{-1}\right)$} & \multicolumn{3}{|c|}{ 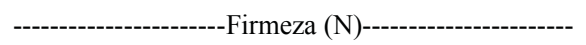 } & \multicolumn{3}{|c|}{ 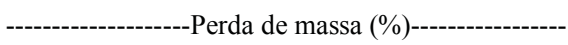 } \\
\hline & \multicolumn{3}{|c|}{---'Dias de armazenamento--- } & \multicolumn{3}{|c|}{-------------Dias de armazenamento------------- } \\
\hline & 45 & 90 & 135 & 45 & 90 & 135 \\
\hline $0 \mathrm{CV}(\%)$ & 44,5 Aa 5,32 & 37,6 Aa 4,22 & $24,2 \mathrm{Ab} 4,13$ & $2,5 \mathrm{Ab} 8,05$ & $5,0 \mathrm{Bb} 7,52$ & 8,9 Aa 13,5 \\
\hline $10 \mathrm{CV}(\%)$ & 39,2 Aa 1,40 & 37,2 Аa 4,50 & $25,8 \mathrm{Ab} 1,78$ & $3,8 \mathrm{Ab} 7,88$ & $4,3 \mathrm{Bb} 5,42$ & 10,6 Aa 3,01 \\
\hline $50 \mathrm{CV}(\%)$ & 40,9 Aa 5,05 & 35,4 Aa 2,13 & $29,3 \mathrm{Ab} 6,30$ & $2,3 \mathrm{Ab} 9,16$ & 6,5 Aa 8,28 & 9,4 Aa 12,24 \\
\hline $100 \mathrm{CV}(\%)$ & 35,8 Аа 6,19 & 39,1 Aa 4,32 & $27,4 \mathrm{Ab} 1,13$ & $3,1 \mathrm{Ab} 3,95$ & $4,3 \mathrm{Bb} 7,47$ & $9,1 \mathrm{Aa} 4,56$ \\
\hline $500 \mathrm{CV}(\%)$ & 36,2 Aa 4,12 & 38,0 Aa 5,70 & $28,9 \mathrm{Ab} 4,30$ & $2,1 \mathrm{Ab} 9,24$ & $5,2 \mathrm{Bb} 6,51$ & 7,0 Aa 12,89 \\
\hline
\end{tabular}

Médias com letras minúsculas iguais na mesma linha e maiúsculas na coluna não diferem significativamente entre si pelo teste de ScottKnott a $5 \%$ de probabilidade de erro. 
Tabela 3 - Sólidos solúveis e relação sólidos solúveis:acidez em maçã cv. 'Eva' aos 45, 90 e 135 dias de armazenamento refrigerado a $0,5^{\circ} \mathrm{C}$ $( \pm 0,2)$ em função da aplicação de 1-MCP, em diferentes doses antes do armazenamento.

\begin{tabular}{|c|c|c|c|c|c|c|}
\hline \multirow{3}{*}{ Doses 1-MCP (mg L $\left.{ }^{-1}\right)$} & \multicolumn{3}{|c|}{ 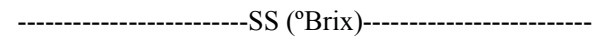 } & \multicolumn{3}{|c|}{---------------Sólidos solúveis:acidez----------------' } \\
\hline & \multicolumn{3}{|c|}{-----------------Dias de armazenamento--------------- } & \multicolumn{3}{|c|}{----------------Dias de armazenamento---- ------------ } \\
\hline & 45 & 90 & 135 & 45 & 90 & 135 \\
\hline $0 \mathrm{CV}(\%)$ & $13,2 \mathrm{Ab} 2,19$ & $12,5 \mathrm{Ab} \mathrm{4,00}$ & 14,8 Aa 7,01 & 22,8 Aa 2,35 & 24,5 Aa 7,71 & 28,4 Aa 9,21 \\
\hline $10 \mathrm{CV}(\%)$ & $14,2 \mathrm{Aa} 4,16$ & $11,0 \mathrm{Ab} 4,54$ & $13,0 \mathrm{Bb} 7,66$ & 26,8 Aa 1,49 & $17,6 \mathrm{Bb} 7,60$ & $15,1 \mathrm{Bb} 9,72$ \\
\hline $50 \mathrm{CV}(\%)$ & 14,2 Аa 5,39 & $11,3 \mathrm{Ab} 7,82$ & $12,6 \mathrm{Bb} 2,27$ & 26,8 Aa 1,20 & $16,8 \mathrm{Bb} 7,94$ & $15,8 \mathrm{Bb} 8,45$ \\
\hline $100 \mathrm{CV}(\%)$ & $14,3 \mathrm{Aa} 4,02$ & $10,8 \mathrm{Ab} \mathrm{2,66}$ & $13,0 \mathrm{Ba} 6,66$ & 26,0 Aa 5,07 & $16,2 \mathrm{Bb} 7,70$ & $20,1 \mathrm{Bb} 8,11$ \\
\hline $500 \mathrm{CV}(\%)$ & $14,2 \mathrm{Aa} 2,03$ & $10,6 \mathrm{Ab} 5,41$ & $13,8 \mathrm{Aa} 2,08$ & 25,9 Aa 2,52 & $16,3 \mathrm{Bb} 9,24$ & 26,0 Aa 10,05 \\
\hline
\end{tabular}

Médias com letras minúsculas iguais na mesma linha e maiúsculas na coluna não diferem significativamente entre si pelo teste de ScottKnott a 5\% de probabilidade de erro.

da transformação das reservas acumuladas durante a formação e o desenvolvimento desses sólidos em açúcares solúveis. Quanto mais baixa for a razão entre sólidos solúveis e acidez titulável, mais interessante é o fruto para os processos industriais. Nesse contexto, amostras com valores inferiores a 20 são de maior interesse do ponto de vista industrial, pois apresentam elevado teor de acidez (CZELUSNIAK et al., 2003). Como pode ser observado na tabela 3 , as maçãs da cultivar 'Eva' encontram-se com valor acima de 20 para a relação sólidos solúveis e acidez titulável no primeiro dia de avaliação, o que demonstra que os frutos estão aptos para consumo ao natural. É importante observar que os frutos controle apresentaram um comportamento diferente dos demais, mantendo a relação sólidos solúveis e acidez semelhante estatisticamente com o passar do tempo de armazenamento refrigerado, devido, provavelmente, ao processo de amadurecimento. Ainda, frutos tratados com a dose de $500 \mathrm{mg} \mathrm{L}^{-1}$ foram semelhantes estatisticamente ao controle no último dia, afirmando mais uma vez a semelhança desses frutos com frutos controle. Assim, do ponto de vista metabólico, esse comportamento pode ser explicado por maior atividade metabólica das maçãs que não receberam o 1-MCP.

$\mathrm{O}$ valor de $\mathrm{L}^{*}$ não mostrou diferença estatística, estando os valores entre 66,2 e 75,7. Os parâmetros de cor $\mathrm{C}$ e $\mathrm{h}^{\circ}$ de maçãs da cultivar 'Eva' durante o armazenamento refrigerado estão apresentados na tabela 4. O parâmetro C de cor, que representa a cromaticidade das amostras, independente do tratamento, apresentou diferença somente no último tempo de armazenamento, quando os frutos apresentavam cor mais intensa. O ângulo Hue mostra que, aos 135 dias de armazenamento, os frutos controle e tratados com as doses de $100 \mathrm{e}$ $500 \mathrm{mg} \mathrm{L}^{-1}$ apresentavam uma cor de fundo levemente menos amarela do que os demais, evidenciando então, frutos mais maduros ao final do período experimental. De acordo com LARRIGAUDIÈRE

Tabela 4 - Cor de fundo da epiderme $\left(\mathrm{C}\right.$ e $\left.\mathrm{h}^{\circ}\right)$ em maçã cv. 'Eva' aos 45, 90 e 135 dias de armazenamento refrigerado a $0,5^{\circ} \mathrm{C}( \pm 0,2)$ em função da aplicação de 1-MCP, em diferentes doses antes do armazenamento.

-Cor de fundo da epiderme-

Doses 1-MCP (mg L $\left.{ }^{-1}\right)$

$-\mathrm{C}-$

Dias de armazenamento-

$-h^{\circ}$

\begin{tabular}{|c|c|c|c|c|c|c|}
\hline & 45 & 90 & 135 & 45 & 90 & 135 \\
\hline $0 \mathrm{CV}(\%)$ & $41,1 \mathrm{Ab} 0,84$ & $45,0 \mathrm{Ab} 1,35$ & 52,1 Aa 2,55 & $98,7 \mathrm{Aa} 2,16$ & $96,4 \mathrm{Aa} 2,04$ & $89,1 \mathrm{Bb} 1,38$ \\
\hline $10 \mathrm{CV}(\%)$ & $40,4 \mathrm{Ab} 2,22$ & $43,8 \mathrm{Ab} 1,41$ & 50,1 Aa 1,63 & 97,1 Aa 1,58 & 95,7 Aa 1,22 & 99,3 Aa 0,74 \\
\hline $50 \mathrm{CV}(\%)$ & $38,0 \mathrm{Ab} 0,26$ & $42,7 \mathrm{Ab} \mathrm{2,34}$ & 53,6 Аa 1,89 & $97,3 \mathrm{Aa} 0,97$ & $96,3 \mathrm{Aa} 2,04$ & 97,6 Aa 1,23 \\
\hline 100 CV (\%) & $39,1 \mathrm{Ab} 0,44$ & $43,7 \mathrm{Ab} \mathrm{2,42}$ & 52,6 Aa 0,50 & 99,8 Аa 1,32 & 97,6 Aa 2,83 & $84,9 \mathrm{Bb} 2,24$ \\
\hline 500 CV (\%) & $39,8 \mathrm{Ab} 2,48$ & $42,3 \mathrm{Ab} \mathrm{2,93}$ & 53,4 Aa 2,23 & 97,9 Аa 2,32 & $98,6 \mathrm{Aa} 0,40$ & $88,8 \mathrm{Bb} 0,52$ \\
\hline
\end{tabular}

Médias com letras minúsculas iguais na mesma linha e maiúsculas na coluna não diferem significativamente entre si pelo teste de ScottKnott a 5\% de probabilidade de erro. 
et al. (2008), a mudança de cor da maçã durante a maturação é dependente de etileno, desse modo, é possível afirmar que o 1-MCP possui forte ação na inibição do etileno em maçãs da cultivar 'Eva' quando aplicado nas doses de 10 e $50 \mathrm{mg} \mathrm{L}^{-1}$.

\section{CONCLUSÃO}

A aplicação do 1-MCP em maçãs da cultivar 'Eva' mostrou-se eficaz ao reduzir a produção de etileno e estender o pico climatérico dos frutos, sendo que, quando utilizado na dose de $100 \mathrm{mg} \mathrm{L}^{-1}$ manteve a produção de etileno constante ao longo do armazenamento. Ainda, a dose de $100 \mathrm{mg} \mathrm{L}^{-1}$ juntamente com as doses de 10 e $50 \mathrm{mg} \mathrm{L}^{-1}$ forneceram uma menor relação sólidos solúveis e acidez titulável ao final dos 135 dias de conservação, quando os frutos tratados com essas doses mostraram diferenças em relação ao ângulo de cor, apresentando-se mais amarelos que os demais.

\section{AGRADECIMENTOS}

Os autores agradecem à Fundação de Amparo à Pesquisa do estado de Minas Gerais (FAPEMIG) e à Coordenação de Aperfeiçoamento de Pessoal de Nível Superior (CAPES), pelo apoio financeiro recebido e à Estação Experimental da Epamig de Lavras, pelo apoio durante a execução do projeto.

\section{REFERÊNCIAS}

AMBAW, A. et al. Modeling the diffusion-adsorption kinetics of 1-methylcyclopropene (1-MCP) in apple fruit and non-target materials in storage rooms. Journal of Food Engineering London, v.102, p.257-265, 2011. Disponível em: <http://www. sciencedirect.com/science/article/pii/S0260877410004280>. Acesso em: 01 ago. 2012. doi: 10.1016/j.jfoodeng.2010.08.028.

ANTUNES, L.E.C. et al.Conservação pós-colheita de frutos de amoreira-preta. Pesquisa Agropecuária Brasileira, Brasília, v.38, n.3, p.413-419, 2003. Disponível em: <http://www.scielo.br/pdf/ pab/v38n3/v38n3a11.pdf>. Acesso em: 09 nov.2012. doi: 10.1590/ S0100-204X2003000300011

AOAC (ASSOCIATION OF OFFICIAL ANALYTICAL CHEMISTS). Official methods of analysis of the association of the official analytical chemists. 18.ed. Washington, 2007. 1750p.

BRACKMANN, A. et al. Qualidade da maçã cv. Gala tratada com 1-metilciclopropeno. Ciência Rural, Santa Maria, v.34, n.5, p.1415-1420, 2004. Disponível em: <http://www.scielo. br/scielo.php?pid=S0103-84782004000500014\&script $=$ sci abstract\&tlng=pt $>$. Acesso em: 23 jun. 2012. doi: 10.1590/S010384782004000500014 .

BRACKMANN, A. et al. Qualidade da maçã 'Gala' armazenada em atmosfera controlada associada à absorção e ao controle da síntese e da ação do etileno. Ciência Rural, Santa Maria, v.38, p.2151-2156, 2008. Disponível em: <http://www.scielo.br/pdf/cr/ v38n8/a10v38n8.pdf>. Acesso em: 23 mar. 2012. doi: 10.1590/ S0103-84782008000800010.

BRACKMANN, A. et al. Aplicação de 1-metilciclopropeno e absorção de etileno em maçã da cultivar Royal Gala colhida tardiamente. Ciência Rural, Santa Maria, v.40, n.10, p.20742080, 2010. Disponível em: <http://redalyc.uaemex.mx/src/inicio/ ArtPdfRed.jsp?iCve=33119160010>. Acesso em: 23 mar. 2012. doi: $10.1590 / \mathrm{S} 0103-84782010005000157$.

CORRENT, A.R. et al. Uso do 1-metilciclopropeno no controle da maturação de maçãs cv. Royal Gala. Revista Brasileira de Fruticultura, Jaboticabal, v.27, n.2, p.207-210, 2005. Disponível em: <http:/www. scielo.br/scielo.php?pid=S0100-29452005000200006\&script $=$ sci abstract\&tlng-pt>. Acesso em: 01 ago. 2012. doi: 10.1590/S010029452005000200006.

CZELUSNIAK, C. et al. Qualidade de maçãs comerciais produzidas no Brasil: aspectos físico-químicos. Brazilian Journal of Food Technology, Campinas, v.6, p.25-31, 2003. Disponível em: <http:// bj.ital.sp.gov.br/artigos/html/busca/PDF/v6nu109p.pdf >. Acesso em: 12 mar. 2012.

HALL, A.E. et al. Ethylene perception by the ERS1 protein in Arabidopsis. Plant Physiology, Waterbury, v.123, p.14491457, ago, 2000. Disponível em: <http://www.ncbi.nlm.nih.gov/ pubmed/10938361>. Acesso em: 01 ago. 2012. doi: 10.1104/ pp.123.4.1449.

LARRIGAUDIÈRE, C. et al. Comparative study of the effects of 1-MCP treatment on apple quality by instrumental and multivariate analysis. Journal of Science and Food Agriculture, Oxford, v.88, p.1614-1621, 2008. Disponível em: <http://onlinelibrary.wiley. com/doi/10.1002/jsfa.3258/pdf>. Acesso em: 22 mar. 2011.doi: $10.1002 /$ jsfa. 3258 .

HAUAGGE, R.; TSUNETA, M. "IAPAR 75 - Eva", "IAPAR 76 Anabela" e "IAPAR 77 - Carícia" - Novas cultivares de macieira com baixa necessidade em frio. Revista Brasileira de Fruticultura, Jaboticabal, v.21, n.3, p.239-242,1999. Disponível em: <http://agris. fao.org/?query $=\% 2$ BcitationTitle: $\% 22$ Revista $\% 20$ Brasileira $\% 20$ de\%20Fruticultura\%22>. Acesso em: 15 mar. 2013.

LUO, Z.S. et al. Effects of ethylene and 1-methylcyclopropene (1$\mathrm{MCP}$ ) on lignification of postharvest bamboo shoot. Food Chemistry, Barking, v.105, n.2, p.521-527, 2007. Disponível em: <http:// www.sciencedirect.com/science/article/pii/S0308814607003433>. Acesso em: 23 jul. 2012.doi: 10.1016/j.foodchem.2007.04.007.

MA, B. et al. Subcellular localization and membrane topology of the melon ethylene receptor CmERS1. Plant Physiology, Waterbury, v.141, p.587-597, 2006. Disponível em: <http://www. plantphysiol.org/content/141/2/587.short>. Acesso em: 23 jul. 2012. doi: 10.1104/pp.106.080523.

R DEVELOPMENT CORE TEAM. A language and environment for statistical computing. R Foundation for Statistical Computing. Vienna, Austria, 2010. Disponível em: <http://www.R-project. org.>. Acesso em: 16 mar. 2013.

WEI, J. et al. Changes and postharvest regulation of activity and gene expression of enzymes related to cell wall degradation in ripening apple fruit. Postharvest Biology and Technology, Amsterdam, v.56, p.147-154, 2010. 